\title{
Optimization of joint operation of district and distributed heat sources for effective and reliable heat supply to consumers
}

\author{
Ivan Postnikov ${ }^{1, *}$, Valery Stennikov ${ }^{1}$, Andrey Penkovskii ${ }^{1}$ \\ ${ }^{1}$ Melentiev Energy Systems Institute of Siberian Branch of the Russian Academy of Sciences, Laboratory of Heat Supply Systems, \\ 664033 Irkutsk, Russia
}

\begin{abstract}
The problem of optimal load distribution between district and distributed heat sources (heat sources of prosumers) in the district heating systems are considered. The methodical approach and mathematical model for solving this problem are proposed. They are based on methods of the theory of system energy researches, theory of industrial organization, theory of hydraulic circuits, and basic laws of cogeneration. The case study results obtained by using the developed methodology are presented. The potential economic effect of the prosumer adoption under specified conditions is demonstrated. The conclusions and directions for further research are formulated.
\end{abstract}

\section{Introduction}

Modern energy systems are developing according to an integration paradigm. Its main idea is to integrate various energy technologies into single multi-resource supersystems with intelligent control [1-3]. The issues of establishing integrated intelligent power systems (Smart Grid) are the subject of a large number of studies that form a theoretical framework for their successful practical implementation. A rather extensive review of the literature on this subject is given in [4].

Optimization of the generation structure when combining various sources, including distributed and localized sources of prosumers, into a single power supply network is one of the key tasks in control and operation of integrated energy systems. A prosumers that have their sources and/or energy storage systems, basing on the energy consumption and production balance, regulate their consumption to improve the efficiency and reliability of both their own energy supply and the entire energy system. As evidenced by the analysis of publications on prosumers, most of the studies are devoted to their operation within electric power systems [5-11]. The prosumer concept is however no less relevant for district heating systems (DHS) that are the largest fuel consumers, especially in the countries with a cold climate (in Russia, for example, more than $45 \%$ of total fossil fuel consumption goes for heating). In [1214], the authors present methodological and practical studies on the participation of prosumers in district heating in Sweden and Norway.

In the previous studies $[15,16]$ we proposed a model for optimal control of the DHS that involve prosumers with owned heat sources (HS). The model is based on the bi-level programming method. This model demonstrated good performance in calculations, but it does not include the cost components related to the heat network $(\mathrm{HN})$ operation, which is its main disadvantage. This paper presents an alternative approach to the load management of the prosumer HS. The approach takes into account network conditions and constraints, as well as some other factors that are significant for the studied problem.

\section{Mathematical formalization of optimal management of the prosumer HS load in DHS, given network conditions}

Calculated scheme of DHS is represented by a network structure with a corresponding hydraulic circuit, which consists of $m$ nodes and $n$ branches [17]. This structure is defined by ordered sets of nodes $J=\{j: j=1, \ldots, m\}$, including HS nodes $J_{\text {hs }} \subset J$, heat consumer nodes $J_{\mathrm{c}} \subset J$ and branching nodes $J_{\mathrm{o}} \subset J$; and a set of branches (HN sections) $-I=\{i: i=1, \ldots, n\}$ that reflect the specified pair-wise ties between the nodes. The operation process of such a system is modeled with a time interval of 1 hour starting at time $\tau_{\mathrm{o}}$, that corresponds to the calculated heat load, and finishing at the final (calculated) time $\tau_{\Sigma}, \mathrm{h}$. The entire set of time instants is denoted by $T$. A set of heat consumers connected to the DHS will be divided into 2 subsets: $J_{\mathrm{c}}=J_{\mathrm{c}}^{\text {ord }} \cup J_{\mathrm{c}}^{\text {pro }}$, where $J_{\mathrm{c}}^{\text {ord }}-$ ordinary consumers, and $J_{\mathrm{c}}^{\text {pro }}$ - prosumers with their own HS. The total heat demand at node $j$ at time $\tau$ is expressed as follows: 


$$
q_{j \tau}^{\mathrm{c}}=q_{j \tau}^{\text {ord }}+q_{j \tau}^{\text {pro }}, j \in J_{\mathrm{c}}^{\text {ord }} \cap J_{\mathrm{c}}^{\text {pro }},
$$

where $q_{j \tau}^{\text {ord }}$ and $q_{j \tau}^{\text {pro }}$ - heat demand of ordinary consumers and prosumers at node $j$, respectively, $\mathrm{GJ} / \mathrm{h}$.

On the other hand, heat demand of consumers at node $j$ is determined by the Rossander formula [18], according to which heat load at time $\tau$ is determined by the following expressions:

$$
\begin{gathered}
q_{j \tau}^{\mathrm{c}}=q_{j}^{\mathrm{h}_{j}}\left[1-\left(1-\omega_{j}\right)\left(\tau / \tau_{\Sigma}\right)^{\sigma_{j}}\right]+q_{j}^{\mathrm{hw}}, j \in J, \tau \in T ; \\
\omega_{j}=\left(1-\varphi_{j}\right)\left[\left(t_{1}-t_{3}\right) /\left(t_{1}-t_{2}\right)\right], j \in J \\
v_{j}=\left(1-\varphi_{j}\right)\left[\left(t_{1}-t_{4}\right) /\left(t_{1}-t_{2}\right)\right], j \in J \\
\sigma_{j}=\left(v_{j}-\omega_{j}\right) /\left(1-v_{j}\right), j \in J
\end{gathered}
$$

where $q_{j}^{\mathrm{h}}$ - calculated heating load, GJ/h; $q_{j}^{\mathrm{hw}}-$ calculated hot water supply load, GJ/h; $\omega_{j}, v_{j}$ and $\sigma_{j}-$ heat load curve irregularity factors; $\varphi_{j}$ - proportion of hot water supply load; $t_{1}-$ calculated indoor temperature, ${ }^{\circ} \mathrm{C} ; t_{2}, t_{3}, t_{4}$, - ambient air temperature: calculated, corresponding to the beginning of the heating season and average throughout the heating season, respectively, ${ }^{\circ} \mathrm{C}$.

Management of the operation of DHS with prosumers implies the distribution of heat load between the district HS and of prosumer HS according to some criteria that provide the required (expected) parameters of the system operation. Given the above-mentioned conditions, the problem of heat supply management can be mathematically solved using the objective function of the total prosumer costs that represent a sum of the costs of heat purchase from the DHS and the costs of heat selfproduction over the considered time interval:

$$
z_{\Sigma}^{\mathrm{pro}}=\sum_{\tau \in T} \sum_{j \in J_{\mathrm{C}}^{\mathrm{pro}}}\left[c_{\tau}^{\mathrm{h}} \cdot\left(q_{j \tau}^{\mathrm{pro}}-q_{j \tau}^{\mathrm{pro}(\mathrm{hs})}\right)+z_{j \tau}^{\mathrm{pro}(\mathrm{hs})}\right],
$$

where $c_{\tau}^{\mathrm{h}}-$ tariff for the heat supplied from the DHS, $\mathrm{rub} / \mathrm{GJ} ; q_{j \tau}^{\mathrm{pro}(\mathrm{hs})}-$ heat self-production volume at the HS of the $j$-th prosumer, $\mathrm{GJ} / \mathrm{h} ; z_{j \tau}^{\mathrm{pro}(\mathrm{hs})}-$ costs of heat selfproduction at the HS of the $j$-th prosumer, rub.

Modern DHS are regulated natural monopolies where heat tariff for consumers is calculated by summing the specific total costs of heat production and transportation in the DHS and standard profitability of the unified heat supply organization (UHSO). Depending on the individual characteristics of the system and its operating conditions, the profitability level of the UHSO lies in a range of $4-7 \%$ [19]. Thus, the heat tariff within the UHSO is calculated by the following formulas:

$$
c_{\tau}^{\mathrm{h}}=A C(1+R / 100 \%)
$$

$$
A C=\left(\sum_{j \in J_{\mathrm{hs}}} z_{j \tau}^{\mathrm{hs}}+z_{\tau}^{\mathrm{hnw}}\right) / \sum_{j \in J_{\mathrm{hs}}} q_{j \tau}^{\mathrm{hs}},
$$

where $A C$ - specific total heat supply costs, rub/GJ; $R$ - profitability, $\% ; z_{j \tau}^{\mathrm{hs}}-$ heat production costs of the $j$ th heat source, rub; $z_{\tau}^{\text {hnw }}$ - heat transportation costs $(\mathrm{HN}$ operating costs), rub; $q_{j \tau}^{\mathrm{hs}}-$ volume of heat produced by the $j$-th HS, GJ/h.

The costs of heat production by district and distributed HS of prosumers for any time instant $\tau$ can be represented as a quadratic function $[20,21]$, rub:

$$
\begin{gathered}
z_{j \tau}^{\mathrm{hs}}=\alpha_{j}\left(q_{j \tau}^{\mathrm{hs}}\right)^{2}+\beta_{j} q_{j \tau}^{\mathrm{hs}}+\gamma_{j}, \quad j \in J_{\mathrm{hs}} \\
z_{j \tau}^{\mathrm{pro}(\mathrm{hs})}=\alpha_{j}\left(q_{j \tau}^{\mathrm{pro}(\mathrm{hs})}\right)^{2}+\beta_{j} q_{j \tau}^{\mathrm{pro}(\mathrm{hs})}+\gamma_{j}, \\
j \in J_{\mathrm{pro}(\mathrm{hs})}
\end{gathered}
$$

where $\alpha_{j}, \operatorname{rub} /(\mathrm{GJ} / \mathrm{h})^{2}, \quad \beta_{j}, \mathrm{rub} /(\mathrm{GJ} / \mathrm{h}), \quad \gamma_{j}, \mathrm{rub}-$ approximation coefficients of cost characteristic of respective heat sources; $J_{\mathrm{hs}}$ - a subset of the DHS heat sources; $J_{\text {pro(hs) }}$ - a subset of the prosumer heat sources.

The costs of HN include operational (constant) costs and the costs of pumping a heat carrier through the $\mathrm{HN}$ (variable). They are determined by the following analytical dependence [18]:

$$
\begin{gathered}
z_{\tau}^{\mathrm{hnw}}=\sum_{i \in I} z_{i \tau}^{\mathrm{hnw}}=F_{1}+F_{2} \sum_{i \in I} x_{i \tau}^{2}\left|x_{i \tau}\right| s_{i} \\
F_{1}=\frac{f_{\mathrm{c}}}{N_{\text {pump }}} \sum_{i \in I} \ell_{i}\left(a_{i}+b_{i} \ell_{i}^{0.19 u_{i}} \chi_{i}^{0.19 u_{i}} s_{i}{ }^{-0.19 u_{i}}\right), \\
F_{2}=c^{\mathrm{e}} /\left(367 \eta_{\text {pump }}\right)
\end{gathered}
$$

where $F_{1}$ - semi-fixed costs, rub; $F_{2}$ - coefficient of semi-fixed costs of $\mathrm{HN}, \mathrm{rub} ; x_{i \tau}$ - heat carrier flow rate in the $i$-th branch of $\mathrm{HN}$ at time $\tau, \mathrm{t} / \mathrm{h} ; s_{i}$ - coefficient of hydraulic resistance of the $i$-th branch, $\mathrm{mh}^{2} / \mathrm{t}^{2} ; f_{\mathrm{c}}-$ share of semi-fixed and operational costs of $\mathrm{HN}$ (normally taken equal to 0.075 ); $N_{\text {pump }}$ - the number of pump unit operation hours, h/year; $\ell_{i}-$ length of the $i$ th network section, $\mathrm{m} ; a_{i}, b_{i}-$ approximation coefficients of costs for the $i$-th network sections with various diameters; $\chi_{i}$ - coefficient depending on the pipeline roughness of the $i$-th network section; $c^{\mathrm{e}}-$ electricity price, rub/kWh; $\eta_{\text {pump }}$ - pump unit efficiency, $\%$.

The cost of heat transportation is determined by the optimal flow distribution in $\mathrm{HN}$. The mathematical model of flow distribution for each time point $\tau$ in has the following matrix form [17]: 


$$
\begin{gathered}
\mathbf{A} \mathbf{x}_{\tau}=\mathbf{g}_{\tau}, \\
\overline{\mathbf{A}}^{\mathrm{T}} \mathbf{p}_{\tau}=\mathbf{h}_{\tau}-\mathbf{H}_{\tau}, \\
\mathbf{S X}_{\tau} \mathbf{x}_{\tau}=\mathbf{h}_{\tau},
\end{gathered}
$$

where A - matrix of couplings of linearly independent nodes of $\mathrm{HN} ; \overline{\mathbf{A}}^{\mathrm{T}}$ - complete transposed branch and node incidence matrix; $\mathbf{x}_{\tau}$ - vector of heat carrier flow rates in the branches of $\mathrm{HN}$ at time $\tau, \mathrm{t} / \mathrm{h} ; \mathbf{g}_{\tau}$ - vector of flow rates at network nodes at time $\tau, \mathrm{t} / \mathrm{h} ; \mathbf{p}_{\tau}-$ vector of nodal pressure in $\mathrm{HN}$ at time $\tau, \mathrm{mm} \mathrm{wc} ; \mathbf{h}_{\tau}$ - vector of head losses in the network branches at time $\tau, \mathrm{mm}$ wc; $\mathbf{H}_{\tau}-$ vector of acting heads at $\mathrm{HS}$ at time $\tau, \mathrm{mm}$ wc; $\mathbf{S}, \mathbf{X}_{\tau}$ - diagonal matrices of coefficients of hydraulic resistance in the branches, $\mathrm{m} /\left(\mathrm{h}^{2} \mathrm{t}^{2}\right)$, and absolute values of flow rates in them, $t / h$, at time $\tau$.

Heat flow rates at each node $j$ at time $\tau$ are determined depending on mass flow rates by the known relationship [22], GJ/h:

$$
q_{j \tau}=v g_{j \tau} \Delta t
$$

where $v$ - heating capacity of the heat carrier, GJ $/{ }^{\circ} \mathrm{Ckg}$; $g_{j \tau}$ - mass flow rates of a heat carrier at the $\mathrm{j}$-th node, $\mathrm{t} / \mathrm{h} ; \Delta t$ - network water temperature difference in the supply and return pipelines, ${ }^{\circ} \mathrm{C}$.

Thus, according to the above-presented mathematical expressions, the problem of optimal load distribution between district HS (of DHS) and prosumer HS is formulated as follows:

- find the minimum of function (6) that determines the total costs of all prosumers by using the following mathematical expressions:

1) equations (2)-(5), to determine the schedule of heat consumption during the heating season (demand for heat);

2) equations (7) and (8), to determine heat tariff for each calculated time point;

3 ) empirical dependencies (9) and (10), to calculate the operational costs of district HS and distributed HS of prosumers at each time point, respectively;

4) formulas (11)-(13), to calculate the operational costs of HS used to determine the heat tariff in DHS;

5) model (14)-(16) and dependence (17), to calculate the thermal and hydraulic conditions in HN.

Search for optimal solutions to the formulated problem is based on the application of the methods of univariate relaxation (the method of coordinate descent) and iterative approximation. Within the computation cycle, the multidimensional optimization problem is reduced to a one-dimensional one with a step-by-step procedure for improving solutions on the heat production volumes at all HS in the system.

\section{Case study and discussion}

The DHS under consideration is presented in Fig. 1 and consists of one district $\mathrm{HS}(0)$ with an output of $132 \mathrm{GJ} / \mathrm{h}$, 9 consumers (nodes $1-3,7-10$ and 12,13) with total load equal $130 \mathrm{GJ} / \mathrm{h}$ and a circuit $\mathrm{HN}$ consisting of 14 sections (branches) with their characteristics indicated in the Fig. 1. The summary load of consumers is 131.6 $\mathrm{GJ} / \mathrm{h}$ and total length of the $\mathrm{HN}$ is $1150 \mathrm{~m}$.

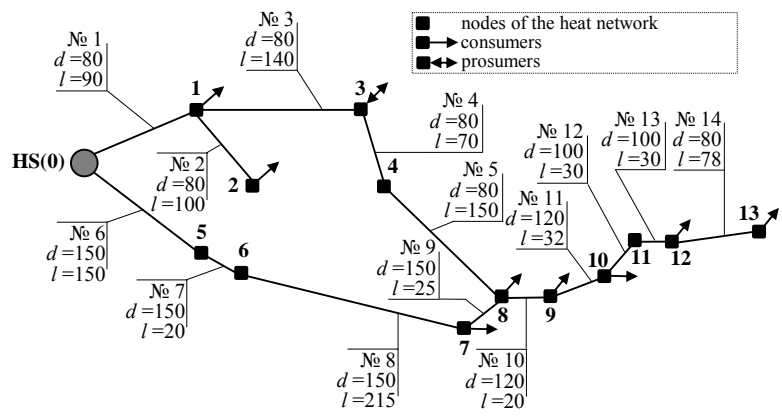

Fig. 1. A calculated scheme of DHS: in the callouts ddiameter of a network section, mm; 1 -length of a network section, $m$

It is assumed that consumer 3 is a prosumer (hereinafter referred to as P3) and has its own HS running on fossil fuel with a capacity of $17 \mathrm{GJ} / \mathrm{h}$, which completely covers designed load of P3. We specify the quadratic cost function (10) for HS P3 with the following values of the approximation coefficients: $\alpha_{j}=$ $0.45 \mathrm{rub} / \mathrm{GJ}^{2} ; \beta_{j}=980 \mathrm{rub} / \mathrm{GJ} ; \gamma_{j}=15864 \mathrm{rub}$. The production costs of $\mathrm{HS}(0)$ are also described by a quadratic function with the following values of the approximation coefficients: $\alpha_{j}=0.25 \mathrm{rub} / \mathrm{GJ}^{2} ; \beta_{j}=380$ $\mathrm{rub} / \mathrm{GJ} ; \gamma_{j}=12047 \mathrm{rub}$.

Fig. 2 demonstrates a diagram describing the total (production + transportation) costs of heat supply to $\mathrm{P} 3$, depending on the load of its HS throughout the entire heating season assumed to be $5000 \mathrm{~h}$. For each time instant, there is a minimum point that corresponds to the optimal loading of the HS P3 (these points lie on line AB). In this case, its value is $25 \%$ for all considered conditions.

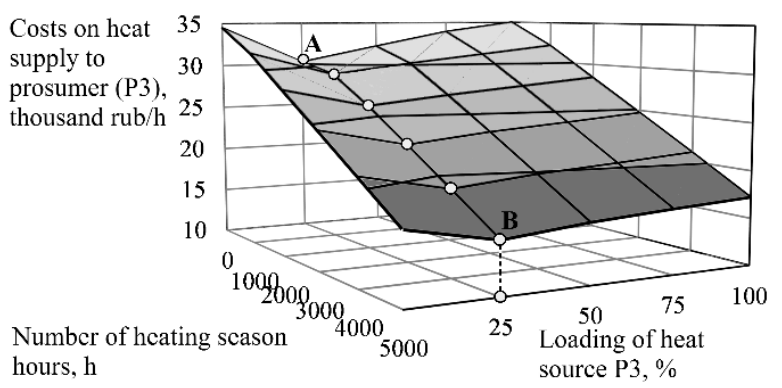

Fig. 2. Change in the costs of heat supply to prosumer 3 (P3) depending on loading of its HS during the heating season

Table 1 presents the indices of optimal load distribution between $\mathrm{HS}(0)$ and HS P3 for heat supply to P3 during the heating season. These data are clearly demonstrated in Fig. 3 where diagram 1 shows the heat 
load curves of P3 with highlighted heat volume generated by $\mathrm{HS}(0)$ and HS P3; diagram 2 illustrates the total (production + transportation) costs of heat supply to P3 that are calculated both with and without the consideration of the prosumer heat source operation.

As evidenced by Figures 3-1 and Table 1, the heat source of prosumer 3 operates during the entire heating season with an output of 1.6-4.1 GJ/h depending on the prosumer load.

Table 1. Results of an optimal load distribution between HS to cover heat load of P3 during the heating season*

\begin{tabular}{|c|c|c|c|c|c|c|}
\hline \multirow[b]{2}{*}{ Indices } & \multicolumn{6}{|c|}{ Number of heating season hours, $\mathrm{h}$} \\
\hline & - & 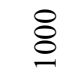 & ¿্ণ & ஓ্ণ & \& & \&̊ำ \\
\hline Load of P3, GJ/h & 16,8 & 11,6 & 9,9 & 8,5 & 7,3 & 6,5 \\
\hline $\begin{array}{l}\text { Loading of the } \\
\text { district HS (0), GJ/h }\end{array}$ & 12,6 & 8,7 & 7,3 & 6,3 & 5,5 & 4,9 \\
\hline $\begin{array}{l}\text { Loading of HS P3, } \\
\text { GJ/h }\end{array}$ & 4,1 & 3,0 & 2,6 & 2,2 & 1,8 & 1,6 \\
\hline $\begin{array}{l}\text { Costs of heat supply } \\
\text { to P3 without HS P3, } \\
\text { thousand rub/h }\end{array}$ & 34,5 & 31,8 & 28,0 & 24,5 & 20,9 & 17,2 \\
\hline $\begin{array}{l}\text { Costs of heat supply } \\
\text { to P3 with HS P3, } \\
\text { thousand rub/h }\end{array}$ & 30,2 & 29,0 & 26,0 & 22,5 & 18,9 & 15,4 \\
\hline $\begin{array}{l}\text { Cost saving owing to } \\
\text { the use of } \mathrm{HS} \mathrm{P} 3 \text {, } \\
\text { thousand rub/h }\end{array}$ & 4,3 & 2,8 & 2,0 & 2,0 & 2,0 & 1,8 \\
\hline
\end{tabular}

*calculations were performed using the "GAMS" software
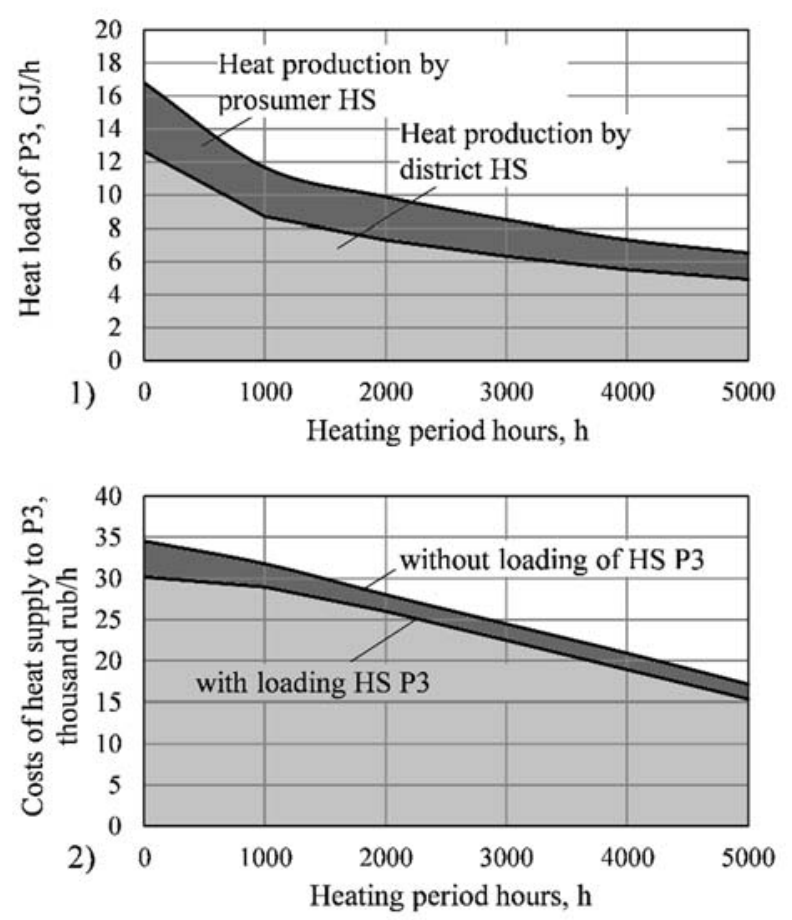

Fig. 3. Indices of the prosumer HS operation in the DHS: 1) optimal loading of the district HS(0) and HS P3; 2) plot of total costs of heat supply to P3 (the area of a dark figure corresponds to an economic benefit owing to the HS P3 loading)

The total heat consumption of P3 over the considered period is about 50.5 thousand GJ, including about 12.6 thousand GJ $(25 \%)$ covered by the prosumer HS.
According to the calculations, it is exactly this ratio of the HS loading that corresponds to the minimum total costs of heat supply to P3. Thus, the specific total costs of heat supply to P3 at the maximum load are 34.5 thousand $\mathrm{rub} / \mathrm{h}$ without the use of the HS P3, and 30.2 thousand $\mathrm{rub} / \mathrm{h}$ when the HS P3 is used. The total costs of heat supply to $\mathrm{P} 3$ from the $\operatorname{HS}(0)$ for the entire heating season is 130.7 million rub. The involvement of the HS P3 reduces this value to 118.3 million rub. Consequently, the economic effect of the HS P3 operation over the considered period is about 12.3 million rubles or $9.4 \%$.

\section{Conclusions}

In this study, we state the problem of managing district heating system with a prosumer, which means an economically-effective load distribution between the heat sources to cover the heat load of the prosumer by using both district heat sources and prosumer heat sources. Solving this problem is based on the search for the conditions that correspond to the minimum production costs of heat supply to the prosumer, including operation of the heat source and heat network. The optimization is performed according to the load curve of consumers, which makes it possible to obtain an integral cost saving estimate for the whole heating period.

The results obtained in the calculation of the test district heating system show the effectiveness of the developed methodology and the possibility of gaining an economic effect when the prosumer heat source is used. An analysis of the results obtained in the test calculations provides the basis for further research in this area.

The research was performed at Melentiev Energy Systems Institute SB RAS under the support of Russian Science Foundation (Grant №17-19-01209).

\section{References}

1. Pierluigi Mancarella. MES (multi-energy systems): An overview of concepts and evaluation models // Energy, 2014, vol. 65, p. 1-17.

2. Pierluigi Mancarella, Göran Andersson, J.A. PeçasLopes, Keith R.W. Bell. Modelling of integrated multienergy systems: Drivers, requirements, and opportunities // Power Systems Computation Conference (PSCC), 2016, Genoa, Italy. DOI: 10.1109/PSCC.2016.7541031. 3. Nikolai I. Voropai, Valery A. Stennikov, Evgeny A. Barakhtenko, Oleg N. Voitov, Ivan V. Postnikov. A Model for Control of Steady State ofIntelligent Integrated Energy System // Energy System Research, 2018, vol. 1(1), p. 57-66.

4. Henrik Lund, Poul Alberg Østergaard, David Connolly, Brian Vad Mathiesen. Smart energy and smart energy systems // Energy, 2017, vol. 137, p. 556-565.

5. Ni Zhang, Yu Yan, Wencong Su. A game-theoretic economic operation of residential distribution system with high participation of distributed electricity 
prosumers // Applied Energy, 2015, vol. 154, p. 471479.

6. Luka Perkovic, Hrvoje Mikulcic, Neven Duic. Multiobjective optimization of a simplified factory model acting as a prosumer on the electricity market // Journal of Cleaner Production, 2017, vol. 167, p. 1438-1449.

7. Hongming Yang, Tonglin Xiong, Jing Qiu et al. Optimal operation of DES/CCHP based regional multienergy prosumer with demand response // Appled Energy, 2016, vol. 167, p. 353-365.

8. Rehman Zafar, Anzar Mahmood, Sohail Razzaq et al. Prosumer based energy management and sharing in smart grid // Renewable and Sustainable Energy Reviews, 2018, vol. 82, p. 1675-1684.

9. Stig Ødegaard Ottesen, Asgeir Tomasgard, Stein-Erik Fleten. Prosumer bidding and scheduling in electricity markets // Energy, 2016, vol. 94, p. 828-843.

10. Dimitrios J. Vergados, Ioannis Mamounakis, Prodromos Makris, Emmanouel Varvarigos. Prosumer clustering into virtual microgrids for cost reduction in renewable energy trading markets // Sustainable Energy, Grids and Networks, 2016, vol. 7, p. 90-103.

11. Lakshmi Prakash, Sugatha Kumari P.R, Sharanya Chandran et al. Self-sufficient Smart Prosumers of Tomorrow // Procedia Technology, 2015, vol. 21, p. 338-344.

12. Lisa Brange, Jessica Englund, Patrick Lauenburg. Prosumers in district heating networks - A Swedish case study // Applied Energy, 2016, vol. 164, p. 492-500.

13. Lisa Brand, Alexandra Calvén, Jessica Englund et al. Smart district heating networks - A simulation study of prosumers' impact on technical parameters in distribution networks // Applied Energy, 2014, vol. 129, p. $39-48$.
14. Hanne Kauko, Karoline Husevåg Kvalsvik, Daniel Rohdeb et al. Dynamic modeling of local district heating grids with prosumers: A case study for Norway // Energy, 2018, vol. 151, p. 261-271.

15. Stennikov V.A., Postnikov I.V., Penkovskii A.V. Methods and models of optimal managing of district heating systems with prosumers // E3S Web of Conferences "Methodological Problems in Reliability Study of Large Energy Systems", 2017, vol. 25, 5 p.

16. Postnikov I.V., Stennikov V.A. Methods and models of ensuring reliability of district heating systems with prosumers // E3S Web of Conferences "Methodological Problems in Reliability Study of Large Energy Systems", 2017, vol. 25, 6 p.

17. Merenkov A.P., Khaselev V.Ya. Theory of hydraulic circuits / Moscow: Nauka, 1985, 278 p.

18. Sennova E.V., Sidler V.G. Mathematical modeling and optimization of developing district heating systems / Novosibirsk: Nauka, 1985, 222 p.

19. Gimadi V.I. The reform that warms: what is expected from reforms in heat supply // Industrial Organization, 2014, No. 4 (46), p. 49-64.

20. Stennikov V.A., Khamisov O.V., Pen kovskii A.V. Optimizing the Heat Market on the Basis of a Two-Level Approach // Thermal Engineering, 2011, vol. 58(12), p. 1043-1048

21. Penkovskii A.V., Stennikov V.A., Khamisov O.V., Mednikova E.E., Postnikov, I.V. Search for a Market Equilibrium in the Oligopoly Heat Market // Energy Procedia, 2017, vol. 105, p. 3158-3163.

22. Sokolov V.Ya. Heating and heating networks / M.: Publishing house of MEI, 1999, $472 \mathrm{p}$. 